\title{
Quantification of Contractility in Stem Cell-Derived Cardiomyocytes
}

\author{
Konrad Brockmeier, Moritz Haustein, Markus Khalil, \\ and Tobias Hannes
}

\begin{abstract}
Murine embryonic stem cell derived cardiomyocytes (mESC-CMs) and murine induced pluripotent stem cell derived cardiomyocytes (miPS-CMs) were differentiated and co-cultured with irreversibly injured myocardial tissue slices. When beating clusters had integrated morphologically into the damaged tissue, isometric force measurements were performed. Effects of $\mathrm{Ca}(2+)$, nifedipine, and betaadrenergic modulation were studied during loaded contractions and compared with the contractile behavior of native murine myocardial slices. Both CM variants conferred force to the myocardial tissue. Contraction increased with higher concentrations of $\mathrm{Ca}(2+)$ and Isoproterenol, and decreased with nifedipine in all slice variants. Differences between mESC-CMs and miPS-CMs were nonsignificant, however, significantly different $(P<0.05)$, when compared to native myocardial slices.
\end{abstract}

\section{Keywords}

Stem cells $\cdot$ iPS $\cdot$ Force measurements $\cdot$ Damaged myocardium

K. Brockmeier $(\bowtie) \cdot$ M. Haustein $\cdot$ T. Hannes

Pediatric Cardiology, University of Cologne, Cologne, Germany

e-mail: konrad.brockmeier@uk-koeln.de

M. Khalil

Pediatric Cardiology, University of Giessen, Giessen, Germany 


\subsection{Introduction}

Therapy for heart failure is a challenge also in the setting of congenital heart disease. Up to now, there is no true solution of a repair of damaged myocytes. Stem cellderived cardiomyocytes are believed to offer possible solutions in the future. The possibility to potentially replace failing myocardium with stem cell-derived cardiomyocytes will depend to a major part on the contractile properties of these cells.

In order to quantify the contractility of stem cell-derived cardiomyocytes, we present an in vitro model using slices of murine ventricles.

The aim of our work was to compare the contractile properties of (1) murine embryonic stem cell-derived cardiomyocytes (mESC-CMs), (2) murine induced pluripotent stem cell-derived cardiomyocytes (miPS-CMs) and (3) contractile properties of native murine ventricular myocardium at a comparable age of differentiation.

As assumed in a prior work, it is almost impossible to assign myocardial contractile properties of transplanted cells in vivo; we therefore developed a tissue culture model mimicking the situation in vivo [1].

\subsection{Materials and Methods}

Experiments were carried out according to the Principles of Laboratory Animal care.

We prepared avital tissue slices from neonatal murine ventricles, which were used as a non-contractile matrix as described elsewhere [2]. In summary, neonatal murine ventricles were embedded in $4 \%$ low-melting agarose and cut into $300-\mu \mathrm{m}$-thick slices along the short axis with a microtome (Leica Microsystems, Wetzlar, Germany), kept in cold $\left(4{ }^{\circ} \mathrm{C}\right) \mathrm{Ca}^{2+}$-free Tyrode's solution, continuously aerated with pure oxygen and supplemented with $\mathrm{CaCl}^{2}$ if needed. Finally, the ventricular tissue slices were exposed to irreversible myocardial injury by severe and long-standing deprivation of oxygen and glucose.

MESC-CMs and miPS-CMs were generated as described previously [3]. Beating clusters of miPS-CMs and mESC-CMs were microdissected 11 days after initiation of in vitro differentiation and co-cultured for 5-7 days on top of the oxygen- and glucosedeprived ventricular slices, placing the non-vital slices into a funnel-shaped cavity and adding $\mathrm{CM}$ clusters in a very cautious way using a score to estimate attachment and "integration" under microscopic control. For the experiments of contractility measurements, those two types of co-culture preparations and native embryonic heart slices were mounted onto two steel needles connected to an isometric force transducer in a customized dish within Tyrode's solution. All three types of slices were conditioned stepwise by extending their length until maximal force resulted during continuous pacing at 2-4 Hz. Signals from the force measurement transducer and electrical pacing were A/D converted, amplified and recorded on a digital medium using DASYLab software (National Instruments) with a sampling rate of $1 \mathrm{kHz}$, high and low pass filtered $(0.05-15 \mathrm{~Hz})$ and signal averaged. Isometric force was measured in Tyrode's solution after $5 \mathrm{~min}$ of spontaneous beating at constant resting conditions. The amplitudes of 20 contractions before and after stimulation were normalized and analyzed. 
Effects of $\mathrm{Ca}^{2+}$ were analyzed in $\mathrm{Ca}^{2+}$-free Tyrode's solution by increasing concentrations of $\mathrm{Ca}^{2+}(0.5,2.5,4.5,6.5$ and $8.5 \mathrm{mM}, 10 \mathrm{~min}$ for each concentration). In addition, the effects of the $\mathrm{Ca}^{2+}$-blocker nifedipine (0.01-10 M) and $\mathrm{B}$-adrenergic isoproterenol (10.9-10.6 M) were analyzed.

Means and standard deviations, and ranges were calculated. Paired and unpaired $\mathrm{t}$ tests or one-way analysis of variance (ANOVA) was performed. $P<0.05$ was considered statistically significant.

\subsection{Results}

Native embryonic heart tissue as well as co-cultured preparations with mESC-CMs or miPS-CMs showed spontaneous contractions. During spontaneous contractions no difference between the beating frequency of preparations with mESC-CMs $[2.9 \pm 0.4(1.3-4.3) \mathrm{Hz}, n=11]$ and miPS-CMs [2.2 $\pm 0.2(1.5-4.0) \mathrm{Hz}, n=12]$ was found. There was significant slower contraction rate in native embryonic heart slices $[0.8 \pm 0.1(0.1-1.4) \mathrm{Hz}, n=8, P<0.05]$. In $\mathrm{Ca}^{2+}$-free Tyrode's solution no contraction occurred. Contraction increased with increasing concentration of $\mathrm{Ca}^{2+}$ in mESC-CMs, miPS-CMs and native embryonic heart slices. Native embryonic heart slices showed significantly stronger contractility $(P<0.05$ vs. both miPS-CMs and mESC-CMs). Comparison was achieved after data normalization using the force values at $\mathrm{Ca}^{2+}=2.5 \mathrm{mM}$ of individual experiments. 3/4 miPS-CMs preparations and 2/4 mESC-CMs preparations showed decreasing contraction at a concentration of $1 \mu \mathrm{mol}$ and stopped contraction at concentrations of $10 \mu \mathrm{mol}$ nifedipine. Native embryonic heart slices continued contractions also at high nifedipine doses. Dosedependent negative inotropy of nifedipine was seen in all three groups (Fig. 55.1).

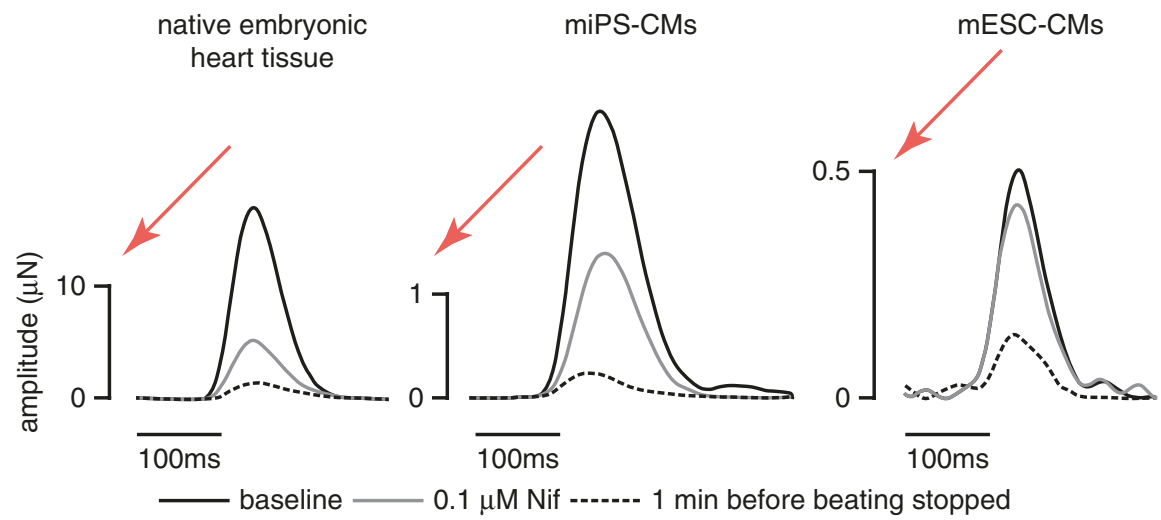

Fig. 55.1 The effect of nifedipin(NIF) is shown in the three preparations: native embryonic heart tissue, murine induced pluripotent cell derived cardiomyocytes (miPS-CMs) and murine embryologic stem cell derived cardiomyocytes (mESC-CMs). Note the similar behavior of all three preparations. Important the different scales of amplitudes (micro Newton)—chosen for relative comparison 
A positive inotropic effect of isoproterenol was seen in all three groups. The inotropic effect of isoproterenol was significantly stronger in native embryonic heart tissue. Differences between mESC-CMs and miPS-CMs were non-significant.

\subsection{Discussion}

The results demonstrate that our ventricular slice model for analysis and comparison of contractility of co-cultured preparations with mESC-CMs, miPS-CMs and native embryonic heart tissue works sufficiently. The primary finding from this study is that stem cell-derived cardiomyocytes, both mESC-CMs and miPS-CMs attached to avital myocardial slices, showed quantifiable force/contractility after co-culture under defined conditions. There were only minor differences between such mESC-CM and miPS-CM preparations. However, significant differences in contraction behavior were found when compared to native embryonic heart slices of comparable age. Calcium dependency was demonstrated in all three preparations in a relative similar fashion, however, in a much lesser amplitude level seen in the pluripotent stem cell-derived cardiomyocyte preparations. MESC-CM and miPSCM slice preparations exhibited contractile behavior of possibly immature sarcoplasmic reticulum. The $\mathrm{Ca}^{2+}$-channel antagonist nifedipine induced a dose-dependent negative inotropy on the force of contraction of all three preparations underlining the importance of L-type calcium channels for contractility regulation. The stem cell-derived cardiomyocytes showed significantly diminished $B$-adrenergic response compared to native embryonic heart slices.

So far there is no data that convincingly support the hypothesis that pluripotent stem cell-derived cardiomyocytes are capable of developing into a cardiomyocyte phenotype that is identical to mature ventricular cardiomyocytes in vitro [4]. The potential development of mature sarcoplasmatic reticulum in stem cell-derived cardiomyocytes is still an issue, and the understanding of factors involved in differentiation toward a functional and a mature cardiac phenotype is still incomplete [5].

\section{References}

1. Pillekamp F, Reppel M, Dinkelacker V, Duan Y, Jazmati N, Bloch W, Brockmeier K, Hescheler J, Fleischmann BK, Koehling R. Force measurements of human embryonic stem cell-derived cardiomyocytes in an in vitro transplantation model. Cell Physiol Biochem. 2007;16:127-32.

2. Pillekamp F, Reppel M, Rubenchyk O, Pfannkuche K, Matzkies M, Bloch W, Sreeram N, Brockmeier K, Hescheler J. Force measurements of human embryonic stem cell-derived cardiomyocytes in an in vitro transplantation model. Stem Cells. 2007;25:174-80.

3. Kolossov E, Bostani T, Roell W, Breitbach M, Pillekamp F, Nygren JM, Sasse P, Rubenchik O, Fries JW, Wenzel D, Geisen C, Xia Y, Lu Z, Duan Y, Kettenhofen R, Jovinge S, Bloch W, Bohlen H, Welz A, Hescheler J, Jacobsen SE, Fleischmann BK. Engraftment of engineered ES cell-derived cardiomyocytes but not BM cells restores contractile function to the infarcted myocardium. J Exp Med. 2006;203:2315-27.

4. Dolnikov K, Shilkrut M, Zeevi-Levin N, Gerecht-Nir S, Amit M, Danon A, Itskovitz-Eldor J, Binah O. Functional properties of human embryonic stem cell-derived cardiomyocytes: 
intracellular $\mathrm{Ca} 2$ handling and the role of sarcoplasmic reticulum in the contraction. Stem Cells. 2006;24:236-45.

5. Xi J, Khalil M, Shishechian N, Hannes T, Pfannkuche K, Liang H, Fatima A, Haustein M, Suhr F, Bloch W, Reppel M, Sarie T, Wernig M, J rnigi R, Brockmeier K, Hescheler J, Pillekamp F. Comparison of contractile behavior of native murine ventricular tissue and cardiomyocytes derived from embryonic or induced pluripotent stem cells. FASEB J. 2010;24:2739-51.

Open Access This chapter is licensed under the terms of the Creative Commons Attribution 4.0 International License (http://creativecommons.org/licenses/by/4.0/), which permits use, sharing, adaptation, distribution and reproduction in any medium or format, as long as you give appropriate credit to the original author(s) and the source, provide a link to the Creative Commons license and indicate if changes were made.

The images or other third party material in this chapter are included in the chapter's Creative Commons license, unless indicated otherwise in a credit line to the material. If material is not included in the chapter's Creative Commons license and your intended use is not permitted by statutory regulation or exceeds the permitted use, you will need to obtain permission directly from the copyright holder. 